\title{
The Impact of Wishful Thinking on the Psychosomatic Health of Children
}

\author{
Oksana N. Dmitrieva ${ }^{1, *}$, Sardana N. Alexeeva ${ }^{1}$, Uliana D. Antipina ${ }^{1}$ and Zekeriya \\ Karadavut $^{2}$
}

${ }^{1}$ M.K. Ammosov North-Eastern Federal University 58, Belinskogo St, Yakutsk, 677000, Russia, ${ }^{2}$ Akdeniz Üniversitesi Edebiyat Fakültesi Dumlupinar Bulvarı Kampüs, Antalya, 07058, Turkey

*Corresponding author. Email: on.dmitrieva@s-vfu.ru

\begin{abstract}
The article describes adapted good wishes for preschool children on the example of Yakut algys. At the beginning of the article, authors point to the need to find methods to eliminate anxiety. The aim of this study was to study the variety of Yakut algys and to choose of the most suitable for the application in the correction of anxiety in preschool age. For the successful selection of differentiated and effective algys, the authors conducted studies of the psychological state of children, which were divided into two groups. For children with high anxiety were used specially selected algys, which contribute to the development of creative thinking, enrich the speech of children, give excellent examples of the native language, imitation of which allows the child not only to master it more successfully, but to adapt adequately in society, thus bring harmony of psycho-emotional development into the life of a preschooler. The article will be of interest to parents, educators and psychologists of preschool institutions. The authors come to the conclusion that the use of adapted works of folklore (certain types of algys) according to their hypothesis will reduce anxiety and increase self-esteem of preschool children.
\end{abstract}

Keywords: wishful thinking, psychosomatic health, preschool children, Yakut algys

\section{INTRODUCTION}

The relevance of this study is that the use of works of ritual poetry of the Yakuts - algys for the development of children is not sufficiently studied. The term algys in Yakut folklore refers to different types of works of ritual poetry - wishes, blessings or spells, hymns, dedicatory chants performed during ceremonies. Handed down from generation to generation, algys preserved the most ancient examples of language, mythological representations and poetic traditions of the people. Reflecting popular philosophy, invaluable evidence of the people's worldview, attitudes, ancestors of nature, and attempts to influence it by the power of the word, algyses play an important role in the life of the Yakuts. They affirm the accepted system of values, support and sanction certain norms of behavior. Their main purpose is that they establish and maintain harmony between nature and man.

\section{THEORETICAL FRAMEWORK}

The first texts of the Yakut algys were collected in the first half of the XVIII century by researchers of the history and ethnography of the Yakuts and political and then by representatives of the Yakut intelligentsia A.E. Kulakovsky, G.V. Ksenofontov and local researchers S.I. Bolo, G.M. Vasilyev, H.I. Konstantinov, A.A. Savvin, G.U. Ergis [1-6]. As one of the genres of Yakut folklore algys were studied N.E. Petrov, V.A. Kondakov [7, 8]. Genre specifics, features of poetics and style of Yakut algys were studied by O.N. Dmitrieva and L.S. Efimova [9, 10].

Currently, one of the urgent tasks is to study the influence of algys on the development of preschool children. The use of good wishes-algyses in everyday life will contribute to the formation of space-time 
representations and the development of imagination, broaden horizons, and increase the level of cognitive, communicative and creative abilities in children in preschool age. Through the works of ritual poetry, the child learns the beauty, conciseness of the native language, joins the culture of his people. The use of works of ritual poetry of the Yakuts - algys creates favorable conditions for the development of speech, thinking of children, motivation of behavior, accumulation of positive moral experience in interpersonal relationships, which will be a support for adaptation in society.

\section{STATEMENT OF THE PROBLEM}

One of the main problems of human health disorders is the increase in the number of children developing disharmoniously and having diseases, as a rule, which are based on psychosomatic disorders.

Timely early diagnosis of the level of anxiety and self-esteem of the child and correction of psychosomatic deviations with the help of oral folk art (good wishes algys) will allow children to develop harmoniously both physically and mentally and also to adapt adequately in society.

The aim of this research was to study the varieties of algys and the choice of the most suitable for the application of the correction of anxiety of preschool age.

To study this problem, the following tasks are set:

1. To determine the level of anxiety and self-esteem of preschool children.

2. To study the variety of algys for differentiated use in children.

3. Expand children's knowledge of the surrounding reality, develop their skills to subtly feel the artistic form,melody and rhythm of the native language.

4. To develop creative, cognitive and communicative abilities of children on the basis of Yakut algyses.

The hypothesis of the study is that, from many algyses one can differentiate the most suitable and successfully use them to correct anxiety and improve the self-esteem of a child of preschool age.

\section{MATERIALS AND METHODS}

The study was conducted at the North-Eastern Federal University among the pupils of the kindergarten № 51 "Keskil" named E.G. Kornilova in Yakutsk, at the age of 5-6 years.

At this stage, the study used:

1. Psychological tests to identify the index of anxiety (test of anxiety by R.Temple, M. Dorkey and
E.W. Amen) projective methods of diagnostics of child "Select the desired face" and the study of parameters of self-evaluation using the method of "Ladder".

Determination of the level of anxiety of the child according to the method of diagnosing the child "Choose the desired person". The method is intended for children 4-7 years old. The degree of anxiety indicates the level of emotional adaptability of the child to social situations, shows the child's attitude to a certain situation, gives indirect information about the nature of the child's relationships with peers and adults in the family and in the team. 14 drawings are used, made in two versions: for a girl, a boy and represents some typical situation for a child's life. The child's face is not drawn in the drawing, only the outline of the head is given. Additionally, two drawings of a child's head are presented. On one - the smiling face of a child, on the other - a sad one. The drawings are shown to the child in a strictly listed order to the questions posed one after another.

1. Play with younger children. "What do you think, what kind of face will the child have: cheerful or sad? $\mathrm{He}$ (she) plays with the kids"

2. A child and a mother with an infant. "What do you think, what kind of face will this child have: sad or cheerful? He (she) is walking with his mother and baby"

3. The object of aggression. "What do you think, what kind of face will this child have: cheerful or sad?"

4. Dressing. "What do you think, what kind of face will this child have sad or cheerful? He (she) is getting dressed"

5. Playing with older children. "What do you think, what kind of face will this child have: cheerful or sad? $\mathrm{He}$ (she) plays with the older children"

6. Going to bed alone. "What do you think, what kind of face will this child have: sad or cheerful? $\mathrm{He}$ (she) is going to bed"

7. Washing. "What do you think, what kind of face will this child have: cheerful or sad? He (she) is in the bathroom"

8. Reprimand. "What do you think, what kind of face will this child have: sad or cheerful?"

9. Ignoring. "What do you think, what kind of face will this child have: cheerful or sad?"

10. Aggressive attack "What do you think, what kind of face will this child have: sad or cheerful?"

11. Collecting toys. "What do you think, what kind of face will this child have: cheerful or sad? He (she) puts away toys"

12. Isolation. "What do you think, what kind of face will this child have: sad or cheerful?" 
13. The child is with his parents. "What do you think, what kind of face will this child have: cheerful or sad? He (she) is with his mom and dad"

14. Eating alone. "What do you think, what kind of face will this child have: sad or cheerful? He (she) eats."

In order to avoid imposing choices on the child, the name of the person is alternated in the instructions. Additional questions are not asked to the child. The results are recorded in a special protocol. Based on the protocol data, the child's anxiety index (IT) is calculated, which is equal to the percentage of the number of emotionally negative choices (sad face) to the total number of drawings (14): IT $=$ (Number of emotional negative choices/14)x100\%. A high level of anxiety is above $50 \%$, an average level is from 20 to $50 \%$ and a low level is from 0 to $20 \%$.

The "Ladder" technique is designed to identify the child's system of ideas about how he evaluates himself, how, in his opinion, other people evaluate him and how these ideas relate to each other.

When studying self-esteem individually, it is possible to identify the reason that formed this or that self-esteem, so that in the future, if necessary, to begin work on correcting difficulties that arise in children.

When working with a child, it is very important to create an atmosphere of trust, openness, and goodwill. The child should have a form with a drawn ladder, a pen or pencil. "Here's the ladder. If you place all the guys on it, then here (show the first step) will be the best guys, here (show the second and third) - good, here (show the fourth) - neither good nor bad guys, here (show the fifth and sixth steps) - bad, and here (show the seventh step) - the worst. What step will you put yourself on? Explain why."

After the child chooses the level of the ladder by the number of the step, the results can be interpreted: step 1 - overestimated self-esteem, steps 2, 3 - adequate self-esteem, step 4 - low self-esteem, steps 5, 6- low self-esteem, step 7 - sharply low self-esteem.

Also, during the tests, the personal qualities of children, the recommendations of their teacher - educator and medical worker were taken into the account;

2. Verbal (conversations, explanation, storyreading);

3. Visual (illustration, audio-media, texts of algyses, multimedia tools);

4. Differentiated selection of algys texts for correction of psychosomatic deviations.

\section{RESULTS AND DISCUSSION}

The study revealed that in the preparatory groups of preschool children, the anxiety index (it) ranges from 42 to $78 \%$ and averages a high level of it in boys $-53.9 \%$, the average level in girls $-49.8 \%$.

The child prone to anxiety is often in a depressed mood, he has poor contacts with the outside world, which frightens him and this leads eventually to low self-esteem and pessimism [11].

This data is confirmed in the results of our study: self-esteem is inadequately overestimated in girls (an average of 9 points) and somewhat underestimated in boys -7.1 points.

Due to the fact that the studied preschool boys have a high anxiety index, it is necessary to develop methods and corrective programs using the works of ritual poetry of the Yakuts - algys to overcome the negative emotional experience.

After the analysis and interpretation of the results of psychological testing, two groups were formed. In the first group, girls with an average level of anxiety and an inadequately inflated self-esteem criterion were identified. The second group included boys with a high level of anxiety and low self-esteem.

For these two groups were selected algyses that take into account not only gender differences, but also reduce the level of anxiety, form a positive attitude of children to themselves, the ability to adequately assess themselves and their activities. In this paper we used the classification of V.A. Kondakov, which distinguishes the following types of algys:

1. Aiyy Domnoro - algys dedicated to the Top Gods;

2. Uot algystara - algys dedicated to earthly deities. They start with summoning the spirit of fire khatan Temeria, spirit of the earth Aan Lahcen Khotun, Baay Bayanay;

3. Yhyakh algystara - Ysyakh algys;

4. Djie-Uot algystara - algys dedicated to home;

5. Yal buoluu algystara - wedding algys;

6. Kihi algyha - algys dedicated to people;

7. Ogo algyha - algys for children [8].

All these algyses are united by a number of common features, namely belief in the magic of the word, performance of them actions, ways to achieve the goal with the help of words and actions, free poetic form, a certain set of general folklore visual means.

Algys of children have the same compositional structure as other algys and consists of three parts. The first part of algys is called "conversion". In this part addressees address to the Deities of the Top, Spiritspatrons of the Middle world. Special attention is paid to children's algys patron's children Aiyysyt and Ieyiekhsit Khotun, the goddess symbolizing fertility, taking care of 
the reproduction of people. Addressees of children's algys are their parents and relatives. In the role of "messages" between a sender and addressees stands algys. The second part is called "petition". In this part the sender with a request to the deities, spirits (ichchi) below, have revealed children's health, well-being, etc. Sender who is a man sends a "message" in the form of algys in which he asks cults of worship a benevolent attitude to the children. The third part of the algys is a description of treats to light deities and Spirits-owners. In many cases, as a "gift" to the deities and spirits owners was given milk, flavored butter, a bundle of horse mane. In some algys the number of semantic parts can vary from one to three.

In children's algys one of the main functions is a communicative function, which is to create a trusting tone in communication and whish makes psychoemotional comfort in interpersonal relationships. A distinctive feature of children's algys is also the creation of a positive attitude and positive emotions in the child.

The first group was recommended the following algys for children:

Sir Iyeni seriedippit aiyylar

Created the Mother earth deity!

Betteh haiyhyn!

Turn around and face me!

Orto doydunu olohtoobut Aiyylar

Who created the Middle World deity!

Michik gynyn!

Give joy!

Yehee Aiyylarbyt ehigi

Urduk aakkytygar sygyryien turan

Bowing before the high name Your most highs,

Kerdestekhput buollun!

Please,

Bihigi dieki sylaas tyynnytynan ilgiian,

Let our childhood be cloudless

Archylyy syldjyn!

Keep and protect us!

Aranachylyy syldjyn!

Emnjic ogo saaspytyn enchireppekke,

Suhuekhputun buduruppekke,

Turukput tupsarygar

Kuusputuger kuus ebin!
May our health be strong,

Excellent condition,

Let the strength increase,

Sangnyar sanaani kyidaan!

Sad thoughts go away!

Tusku! Tusku! Tusku!

Praise! Praise! Praise!

The second group was offered such algys:

Ebugelerim ilin ettuber,

Great glorious my ancestors!

Ebugelerim kelin ettuber,

You protect me everywhere.

Ebugelerim una ettuber,

You are my guiding star,

Ebugelerim khanas ettuber,

You are advisers in everything and always.

Ebugelerim ueheetten,

As long as I remember you,

Ebugelerim allaraattan,

As long as i believe in you,

Ebugelerim ergichchi,

Not afraid of anything,

Ebugelerim teguruchchu,

Not blunt bright eyes,

Ebugelerim iileen-sagalaan,

Nothing can break nor kill me.

Ebugelerim subeleen-amalaan,

Ebugelerim aryallaan-archylaan,

This is my great destiny,

Ildje syldjallar miigin,

This is the purpose of mine!

Tuakhtan da kuttammappyn,

Great glorious my ancestors,

Tuakhtan da tollubappyn,

Tuakh da okhtorbot,

Asking for protection from You,

Tuokh da samnarbat,

Sprinkle Mare's milk in my body!

Aykhalym itinnik, 
It's my destiny!

Aiyllyatym onnuk,

It's my fate!

Aiyn!

The main purpose of pronouncing of these algyses is that with the help of them children can protect themselves from troubles, impure forces, call for health, well-being and happiness, help of their ancestors and create a positive mental attitude. The technique of algys is not just reading and repeating certain words in the right order, but speaking with "thinking", "passing through" each word and with the adoption of the image. Since ancient times, Yakuts had a cult of the word. With the help of algys Yakuts from the ancient times "maintained" a contact with deities, spirits of nature, home, as well as with their patron spirits. It was believed that the recitation of algys will attract the attention of deities-patrons to the request and help to receive for them the "security" protecting force.

\section{CONCLUSION}

The autonomic nervous system is involved in the implementation of both positive and negative emotions, with each emotional state having a characteristic ratio of adrenergic and cholinergic effects. So, at positive and negative emotions in passive behavioral background is dominated by the choline part, and active behavioral background - adrenal.

So, with an increase in the concentration of serotonin in the brain leads to a rise in mood, and reducing it to depression. At the same time, serotonin "depression of anxiety" differs from noradrenalin (with noradrenalin deficiency) "depression of anguish". With an average content of nor epinephrine, adrenaline, serotonin, dopamine and opiates, the behavior is deprived of bright emotionality and acquires the features of "confidence" with a high level of testosterone and a low level of cortical and endorphins. The feeling of "confusion and anxiety" with the release of depression is with an increase in the level of cortical and endorphins and a decrease in testosterone and catecholamine's noradrenalin and serotonin.

Thus, anxiety is associated with neurogenic and endocrine mechanisms of regulation of heart rate and respiration. So, the higher the anxiety, the greater the heart rate, stress index and heart rate coefficient, respiratory movements, increased intestinal motility.

A high level of anxiety negatively affects the socialization of the child, his relationship with adults, with peers, thus, the diagnosis of anxiety at the early stages is even more relevant, since in preschool children anxiety is not yet a stable trait, that is, relatively reversible and it is possible to significantly reduce the anxiety of the child during the relevant psychological, pedagogical and medical procedures [12].

Based on this, it is necessary to develop methods to combat anxiety. In the future, we plan to study in-depth the methods of carrying out and using certain algys for correction of psychosomatic disorders and anxiety states.

\section{REFERENCES}

[1] A.E. Kulakovskiy, The Scientific works, Yakutsk, 1979, $483 \mathrm{p}$.

[2] G.V. Ksenofontov, Allada: materials on mythology and legendary history of Yakutia, Moscow, 1977, $248 \mathrm{p}$.

[3] S.I. Bolo, The life of Yakuts before arrival of Russians to Lena (according to legends of Yakuts of the former Yakut district), Yakutsk, 1938.

[4] M.I. Vasiliev, Kh.I. Konstantinov, Oral traditions of the Yakut people, Yakutsk, 1942, 252 p.

[5] A.A. Savvin, Yakut kumys, Yakutsk, 1948, pp. 117-138.

[6] G.U. Ergis, Essays on Yakut folklore, Moscow, 1974, $396 \mathrm{p}$.

[7] N.E. Petrov, The origin of the Yakuts spiritual and religious religion Aiyy domnoro, Yakutsk, 1998, pp. 132-151.

[8] V.A. Kondakov, The religion Aar Aiyy, Yakutsk, 2011, 532 p.

[9] O.N. Dmitrieva, Milli Folklor 112 (2016) 154-164.

[10] L.S. Efimova, Algys Sakha (Yakuts) in the light of folklore traditions of the Turkic-Mongolian peoples of Siberia: classification, general characteristics, Novosibirsk, 2013, 178 p.

[11] Yu.V. Shcherbatykh, Psychology of fear, Moscow, 2005, 512 p.

[12] S.V. Lukicheva, Anxiety of preschool children (signs, methods, advice to parents (2016). Retrieved from: https://www.b17.ru/article/45696 